Article

\title{
Assessment of Gas Production Potential from Hydrate Reservoir in Qilian Mountain Permafrost Using Five-Spot Horizontal Well System
}

\section{Yun-Pei Liang ${ }^{1,2}$, Xiao-Sen $\mathrm{Li}^{3}$ and $\mathrm{Bo} \mathrm{Li}^{1,2, *}$}

1 State Key Laboratory of Coal Mine Disaster Dynamics and Control, Chongqing University, Chongqing 400044, China; E-Mail: liangyunpei@cqu.edu.cn

2 College of Resources and Environmental Science, Chongqing University, Chongqing 400044, China

3 Key Laboratory of Gas Hydrate, Guangzhou Institute of Energy Conversion, Chinese Academy of Sciences, Guangzhou 510640, China; E-Mail: lixs@ms.giec.ac.cn

* Author to whom correspondence should be addressed; E-Mail: libo86@cqu.edu.cn; Tel.: +86-152-1320-1702.

Academic Editor: Richard Coffin

Received: 31 August 2015 / Accepted: 23 September 2015 / Published: 28 September 2015

\begin{abstract}
The main purpose of this study is to investigate the production behaviors of gas hydrate at site DK-2 in the Qilian Mountain permafrost using the novel five-spot well (5S) system by means of numerical simulation. The whole system is composed of several identical units, and each single unit consists of one injection well and four production wells. All the wells are placed horizontally in the hydrate deposit. The combination method of depressurization and thermal stimulation is employed for hydrate dissociation in the system. Simulation results show that favorable gas production and hydrate dissociation rates, gas-to-water ratio, and energy ratio can be acquired using this kind of multi-well system under suitable heat injection and depressurization driving forces, and the water production rate is manageable in the entire production process under current technology. In addition, another two kinds of two-spot well (2S) systems have also been employed for comparison. It is found that the $5 \mathrm{~S}$ system will be more commercially profitable than the $2 \mathrm{~S}$ configurations for gas production under the same operation conditions. Sensitivity analysis indicates that the gas production performance is dependent on the heat injection rate and the well spacing of the $5 \mathrm{~S}$ system.
\end{abstract}


Keywords: gas hydrate; depressurization; thermal stimulation; five-spot well; Qilian Mountain permafrost

\section{Introduction}

Natural gas hydrates (NGH) are crystalline compounds formed by water and small gas molecules under suitable thermodynamic conditions (low temperature and high pressure). Large quantities of gas hydrates have been demonstrated to be buried in deep marine sediments and in the permafrost through many national research and development programs [1]. In recent years, a lot of scientific drilling and exploration projects have been implemented for the verification of gas hydrate occurrence, the evaluation of its resource potential, and the field testing of the production strategies [2]. For example, natural gas was successfully extracted from gas hydrate in the seafloor in Pacific waters off Japan during the hydrate exploitation research program in 2013, which provided direct evidence for the possibility of gas production from natural oceanic hydrate deposits.

Because of the ever increasing energy demand in China, natural gas hydrates have also been studied as a kind of potential and challenging energy resource in this country. After the gas hydrate samples were obtained in the Shenhu area of the northern South China Sea in May 2007, core samples containing gas hydrate were also successfully collected from the scientific drilling wells in 2008-2009 in the Qilian Mountain permafrost, which is located in the north of the Qinghai-Tibet Plateau Permafrost (QTPP) in China (Figure 1) [3,4]. Four test wells (DK-1, DK-2, DK-3 and DK-4) were accomplished in this exploration project, and the drilling results showed that the gas hydrates were mainly stored in the pores and/or in the fractures [5] of the hydrate-bearing cores, of which the main geological components were sandstone, mudstone, oil shale, and siltstone. Field measurements showed that gas hydrates were mainly distributed in the depth of 133-396 m underground in the Qilian Mountain permafrost [6]. Previous studies indicated that the annual average of the permafrost ground temperature $\left(T_{0}\right)$ was around -1 to $-3{ }^{\circ} \mathrm{C}$. Based on in situ measurements in this area, the geothermal gradients within and below the frozen layers $\left(G_{1}\right.$ and $\left.G_{2}\right)$ of the QTPP were approximately in the range of $0.011-0.033{ }^{\circ} \mathrm{C} / \mathrm{m}$ and $0.028-0.051{ }^{\circ} \mathrm{C} / \mathrm{m}$, respectively $[7,8]$. These thermodynamic conditions are favorable for the formation of natural gas hydrate in the Qilian Mountain.

In order to realize the use of the methane gas trapped in gas hydrates as a kind of energy resource, people have proposed various kinds of production techniques for gas extraction from hydrate deposits, such as depressurization [9-12], thermal stimulation [13-15], inhibitor injection [16,17], and $\mathrm{CO}_{2}$ replacement $[18,19]$. In general, depressurization is considered to be the most practical and economic method for field-scale hydrate decomposition due to its technical effectiveness and the fast propagating rate of the pressure wave [12]. However, the gas production rate is always restricted by the limited sensible heat and heat transfer rate of the hydrate reservoir. Previous studies show that the gas production rates are both located at a low level when using the depressurization method in a single horizontal well [20] and a single vertical well [21] for hydrate dissociation in the Qilian Mountain at site DK-3. However, when the huff and puff method (the combination of depressurization and thermal stimulation) 
is also employed in a single horizontal well [22], the gas production rate can be obviously enhanced because of the additionally provided heat from outside.

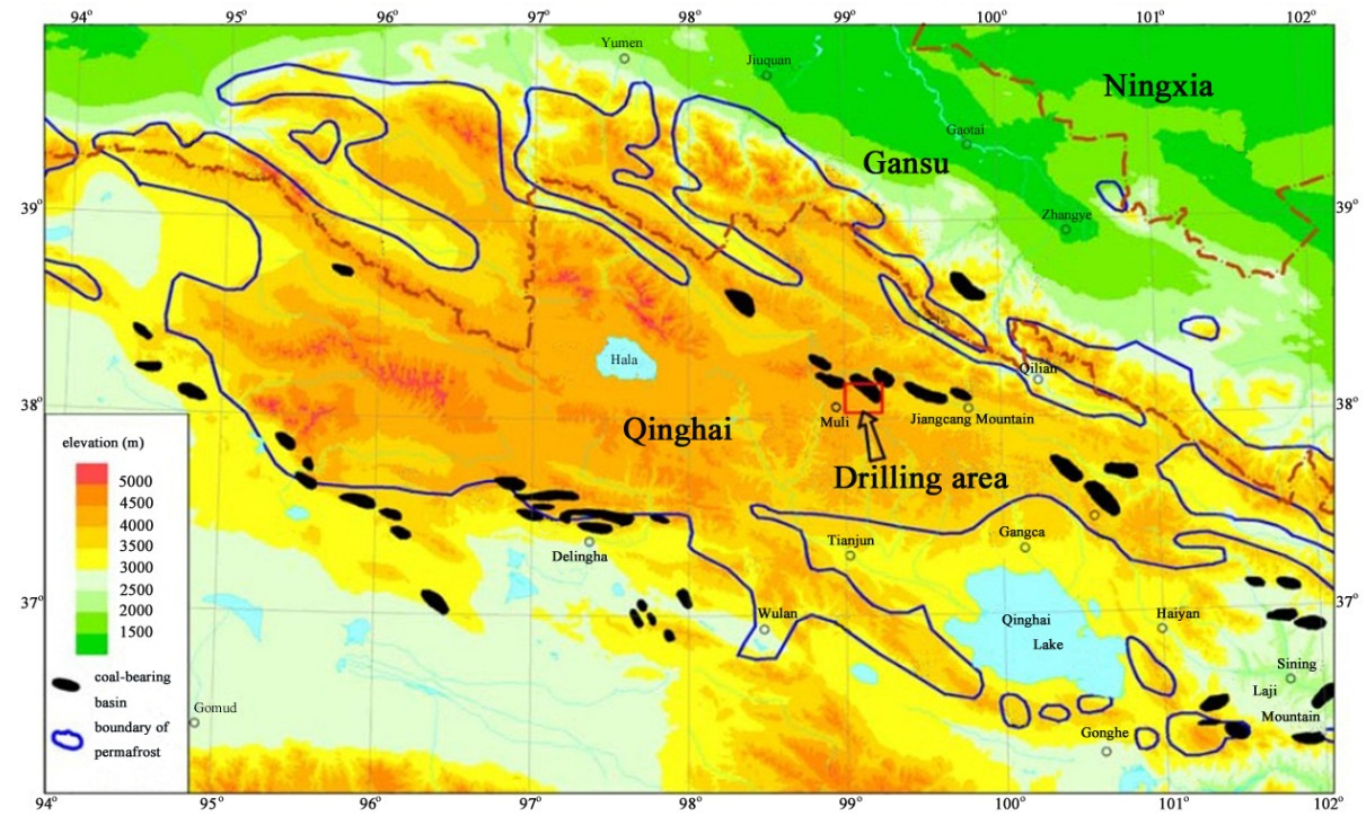

Figure 1. Location map of the Scientific Drilling Project of Gas Hydrate in Qilian Mountain permafrost.

The hydrate dissociation performance in porous media is not only affected by the production methods mentioned above, but also associated with the well designs in the hydrate deposits. Moridis et al. [12] simulated the gas production from the Mount Elbert gas hydrate deposit by depressurization using both vertical and horizontal wells, and the results showed that the horizontal wells could increase the production rates by almost two orders of magnitude when comparing with the vertical wells. After that, Moridis et al. [23] further compared the production behaviors of a single horizontal well design and a two-well design, and found that the gas production rate of the two-well configuration was much higher than that of the single-well design. Combining depressurization and warm brine stimulation methods, Feng et al. [24] investigated the hydrate dissociation performance in the South China Sea in two horizontal wells. It was found that the dual wells placed in the same horizontal plane performed better than those placed in the same vertical plane. Recently, Li et al. [25,26] have also evaluated the gas production potential from Qilian Mountain permafrost at site DK-2 using two kinds of two-spot horizontal well system, as shown in Figure 2a,b. It also indicated that the production efficiency was more favorable than that of the single-well design.

Generally, the single-well design has been proved to be not appropriate for hydrate exploitation in the Qilian Mountain permafrost, while the multi-well configurations with proper production methods may provide tantalizing possibilities for commercial exploitation. The five-spot well system shown in Figure $2 \mathrm{c}$ is one of the typical multi-well patterns which have been widely used in the oil industry to enhance the oil recovery [27-29]. This system can be divided into several identical units because of symmetry. Each single unit consists of one injection well in the center and four production wells near the corner of the rectangle. Every production well belongs to two adjacent units. Therefore, there are actually 3 wells in each single unit. Recently, Wang et al. [15,30] have investigated the production 
behaviors of gas hydrate using five-spot well with different methods in a cubic hydrate simulator. It was demonstrated that this kind of well design was effective for hydrate dissociation in porous media. In addition, the results showed that the five-spot well could provide more favorable production efficiency than the single well design when using the same dissociation methods. Up to now, the five-spot well system shown in Figure $2 \mathrm{c}$ has not been employed for the exploitation of the field-scale hydrate reservoirs.

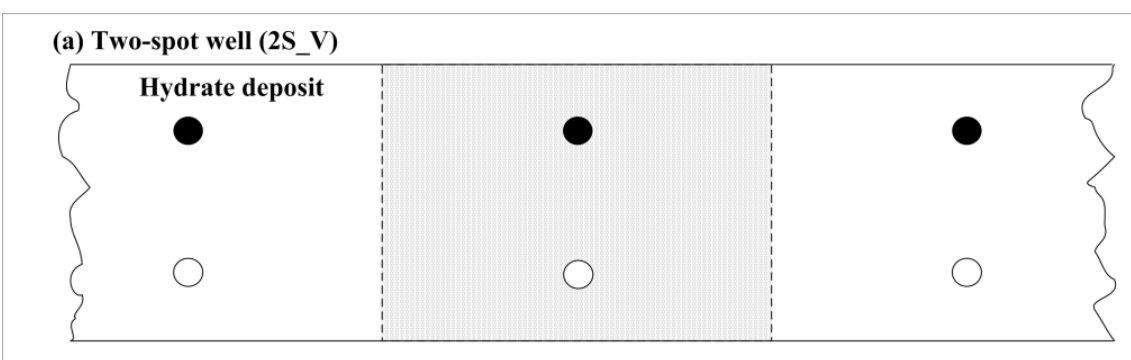

(b) Two-spot well (2S_H)

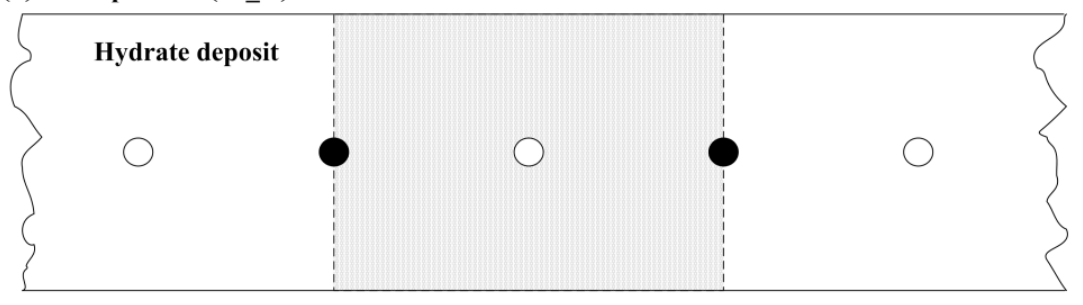

(c) Five-spot well (5S)

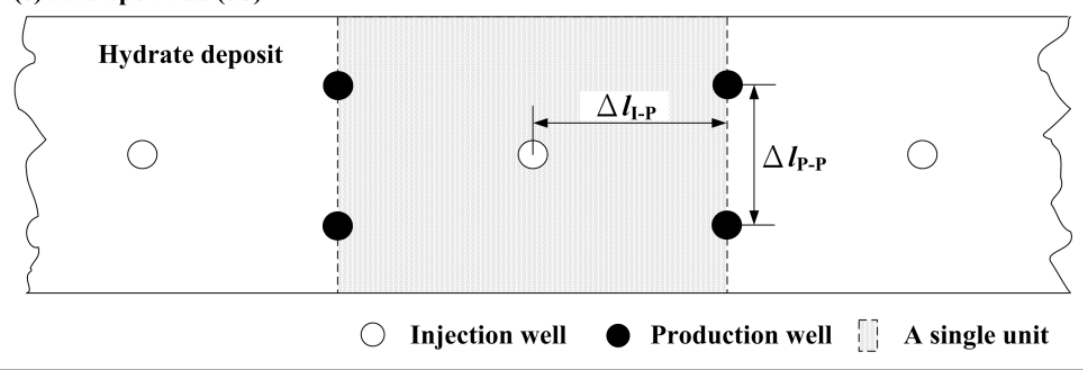

Figure 2. Two-spot and five-spot horizontal well systems in the hydrate deposits.

This numerical study is mainly concerned about the assessment of the gas production potential from Qilian Mountain permafrost hydrate deposits using the novel five-spot well system. Field measurements show that the thickest hydrate layer is located in the depth of 235.0-291.3 $\mathrm{m}$ at site DK-2 [4], which may be more profitable for the possible commercial exploitation. Therefore, the wells are placed in this interval to conduct the production process. We only investigate the performance of the horizontal wells because of their obvious advantages over vertical wells reported in previous studies [12,25]. In addition, the two-spot well systems in Figure 2a,b are also employed for the purpose of comparison. The dependence of the gas production on the well spacing is also studied through sensitivity analysis.

\section{Production Method and Well Configuration}

\subsection{Production Methods}

As the hydrate layer mentioned above is close to the permafrost area, the pressure and temperature in this layer are estimated to be in the range of 3.63-4.19 $\mathrm{MPa}$ and 3.26-4.69 ${ }^{\circ} \mathrm{C}$, respectively. Thus, the 
sensible heat of the hydrate reservoir is very limited, and pure depressurization method is not appropriate in this permafrost area $[20,21]$. Previous studies $[14,15]$ have demonstrated that the gas production under depressurization could be obviously enhanced when the additional heat is supplied from outside, while pure thermal stimulation will act inefficiently if it is used alone for hydrate decomposition. Therefore, the combination of depressurization and thermal stimulation is introduced as the production method in the five-spot and two-spot well systems in this study.

\subsection{Five-Spot Well Design}

The five-spot well (5S for short) system shown in Figure $2 \mathrm{c}$ is employed for hydrate dissociation in the Qilian Mountain. All the wells are positioned horizontally in the hydrate layer, and we only consider a single rectangular unit due to the symmetrical property of the system. Each unit consists of five horizontal wells: an injector in the center for heat injection and four producers near the corner for gas production. The horizontal distance between the injector and the producer is $\Delta l_{\text {I-P }}$, and the vertical distance between the producers is $\Delta l$ P-P. Once the production process starts, heat is supplied to the hydrate deposit continually from the central horizontal well by circulating hot water in the well or through electrical or microwave heating. No mass is injected into the reservoir because of the low permeability of the porous media. Meanwhile, the other four wells are operated under a constant bottomhole pressure $P_{\mathrm{W}}$ to produce the fluids from the deposit. The wellbores are regarded as a pseudo-porous medium with $\Phi=1.0, k=5.0 \times 10^{-9} \mathrm{~m}^{2}$ (5000 Darcies) and a capillary pressure $P_{\text {cap }}=0$ [22]. In addition, the two kinds of two-spot horizontal well systems in Figure 2a,b (named as 2S_V and 2S_H, respectively) are also employed to compare with the production performance of the $5 \mathrm{~S}$ system under the same operation conditions.

\section{Numerical Models and Simulation Approach}

\subsection{Numerical Simulation Code}

The parallel version of the TOUGH + HYDRATE $(\mathrm{T}+\mathrm{H})$ code is used to conduct the numerical simulation in this study [31]. The $\mathrm{T}+\mathrm{H}$ is a compositional code which can model multi-phase and multi-component reactions of hydrate formation and/or dissociation in complex geologic media. It includes both an equilibrium and a kinetic model, which have been validated or modified by Li et al. [14,32-34] based on experiments of two hydrate simulators. In addition, the comparisons of the two submodels indicate that the equilibrium model is more preferred to predict the production behaviors of field-scale hydrate deposits [10]. Therefore, the equilibrium model is chosen to describe the dissociation process of gas hydrate in the Qilian Mountain.

\subsection{Geometry, Domain Discretization, and System Properties}

The system properties and simulation parameters of the hydrate deposits at site DK-2 in the Qilian Mountain are shown in Table 1, which is based on the field measurement data and some published results $[4,25,26]$. The geometry and the configuration of the hydrate deposit with five-spot horizontal well system are shown in Figure 3a. Only a single unit is simulated because of symmetry. Each unit contains one injection well (Well_0) and four production wells (Well_1-Well_4) which are all 
positioned in the $56 \mathrm{~m}$-thick hydrate-bearing layer (HBL, $-28.0 \leq z \leq 28.0 \mathrm{~m}$ ). However, only a half of each production well belongs to this single section. In the Cartesian coordinate system, Well_0 is located at $(22.5,0)$, while Well_1-Well_4 are positioned at $(0,10),(45,10),(0,-10)$, and $(45,-10)$, respectively. Thus, the $\Delta l_{\mathrm{I} \text {-P }}$ and $\Delta l_{\mathrm{P}-\mathrm{P}}$ are 22.5 and $20.0 \mathrm{~m}$, respectively. The HBL is sandwiched by another two $21.5 \mathrm{~m}$-thick boundary layers: the overburden layer (OB, $28.0 \leq z \leq 49.5 \mathrm{~m})$ and the underburden layer (UB, $-49.5 \leq z \leq-28.0 \mathrm{~m}$ ), which have the same flow properties with the HBL. Assuming uniform properties of the horizontal wells along the $y$ axis, only a single unit of $\Delta y=1 \mathrm{~m}$ is needed to be simulated.

Table 1. Physical properties and simulation models at site DK-2 in Qilian Mountain permafrost.

\begin{tabular}{|c|c|}
\hline Parameter & Value \\
\hline Thickness of hydrate zone & $56.0 \mathrm{~m}$ \\
\hline Thickness of OB and UB & $21.5 \mathrm{~m}$ \\
\hline Position of HBL below the ground & $235 \mathrm{~m}$ \\
\hline Distance between injector and producer $\Delta l_{\mathrm{I}-\mathrm{P}}$ & $22.5 \mathrm{~m}$ \\
\hline Distance between two producers $\Delta l_{\text {P-P }}$ & $20.0 \mathrm{~m}$ \\
\hline Gas composition & $100 \% \mathrm{CH}_{4}$ \\
\hline Initial phase saturations in the HBL & $S_{\mathrm{H}}=0.40, S_{\mathrm{A}}=0.60$ \\
\hline Permafrost ground temperature & $T_{0}=271.56 \mathrm{~K}$ \\
\hline Thermal gradient & $G_{1}=0.013^{\circ} \mathrm{C} \cdot \mathrm{m}^{-1}$ \\
\hline (within and below the frozen layer) & $G_{2}=0.028^{\circ} \mathrm{C} \cdot \mathrm{m}^{-1}$ \\
\hline Intrinsic permeability of the porous media & $k=1 \mathrm{mD}$ \\
\hline Media porosity $\Phi$ & 0.30 \\
\hline Composite thermal conductivity model [31] & $k_{\Theta \mathrm{C}}=k_{\Theta \mathrm{RD}}+\left(S_{\mathrm{A}}^{1 / 2}+S_{\mathrm{H}}^{1 / 2}\right)\left(k_{\Theta \mathrm{RW}}-k_{\Theta \mathrm{RD}}\right)+\Phi S_{\mathrm{I}} k_{\Theta \mathrm{I}}$ \\
\hline$k_{\Theta \mathrm{RD}}$ & $1.0 \mathrm{~W} /(\mathrm{m} \mathrm{K})$ \\
\hline$k_{\Theta \mathrm{RW}}$ & $3.1 \mathrm{~W} /(\mathrm{m} \mathrm{K})$ \\
\hline Capillary pressure model [35] & $\begin{array}{l}P_{\text {cap }}=-P_{01}\left(\left(S^{*}\right)^{-1 / \lambda}-1\right)^{1-\lambda} \\
S^{*}=\left(S_{\mathrm{A}}-S_{\mathrm{irA}}\right) /\left(1-S_{\mathrm{irA}}\right)\end{array}$ \\
\hline$S_{\text {irA }}$ & $0.29[22]$ \\
\hline$\lambda$ & 0.45 \\
\hline$P_{01}$ & $10^{5} \mathrm{~Pa}$ \\
\hline Relative permeability Model [31] & $\begin{array}{l}k_{\mathrm{rA}}=\left(S_{\mathrm{A}} *\right)^{n} \\
k_{\mathrm{rG}}=\left(S_{\mathrm{G}} *\right)^{n G} \\
S_{\mathrm{A}}{ }^{*}=\left(S_{\mathrm{A}}-S_{\mathrm{irA}}\right) /\left(1-S_{\mathrm{irA}}\right) \\
S_{\mathrm{G}}{ }^{*}=\left(S_{\mathrm{G}}-S_{\mathrm{irG}}\right) /\left(1-S_{\mathrm{irA}}\right)\end{array}$ \\
\hline$n$ & $3.572[22]$ \\
\hline$n_{\mathrm{G}}$ & 3.572 \\
\hline$S_{\mathrm{irG}}$ & 0.05 \\
\hline$S_{\text {irA }}$ & 0.30 \\
\hline
\end{tabular}

The two-dimensional (2-D) hybrid grid in Figure 3 b consists of 13,540 elements. A fine discretization is applied to the HBL to obtain accurate predictions of gas production and to precisely capture the evolutions of the matter distributions in this area. Because of the violent physical and chemical processes in the vicinity of the wellbores, a refined cylindrical-shaped mesh is used in the area of $r<3.0 \mathrm{~m}$ around the center of each well, and then a radially graded mesh is discretized to connect the cylindrical mesh with the outside brick gridblocks. During the simulation process, fluids are produced through four 
gridblocks of the first cylindrical layer $(r=0.1 \mathrm{~m})$ by reducing their pressures to be lower than the initial level. The uppermost and lowermost layers in Figure $3 \mathrm{~b}$ are the inactive boundaries with constant thermodynamic properties. This grid results in 54,160 coupled equations to be solved simultaneously under the equilibrium reaction regime without inhibitor.

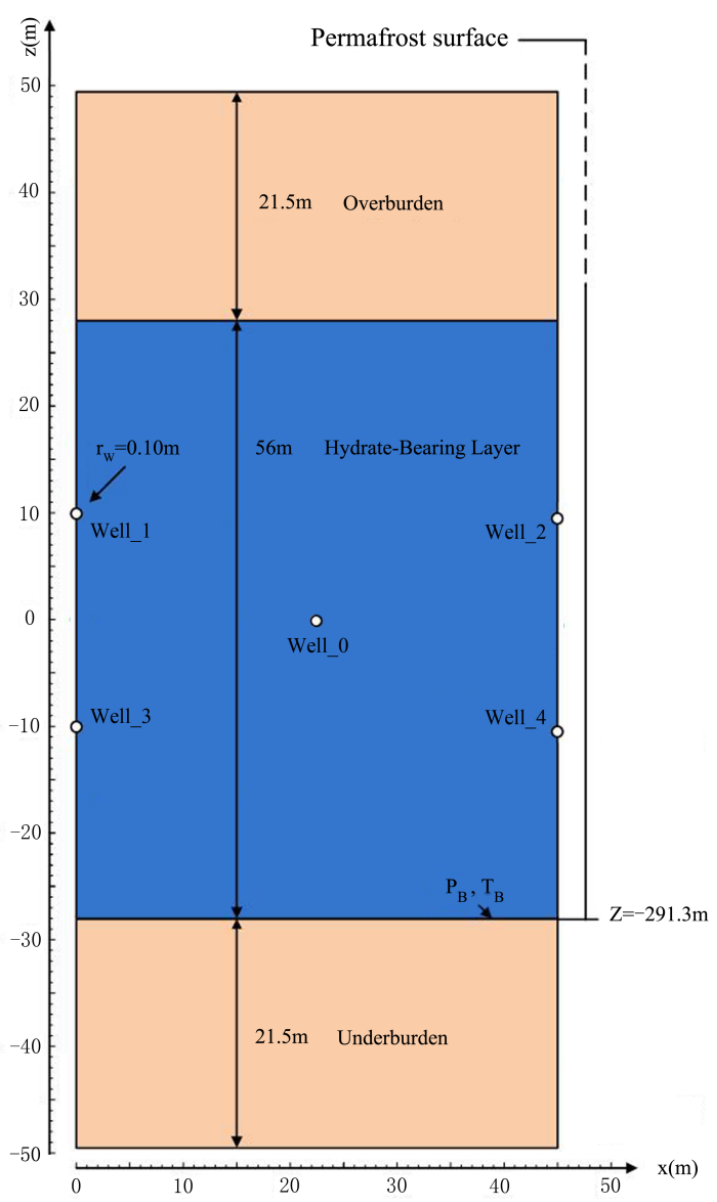

(a)

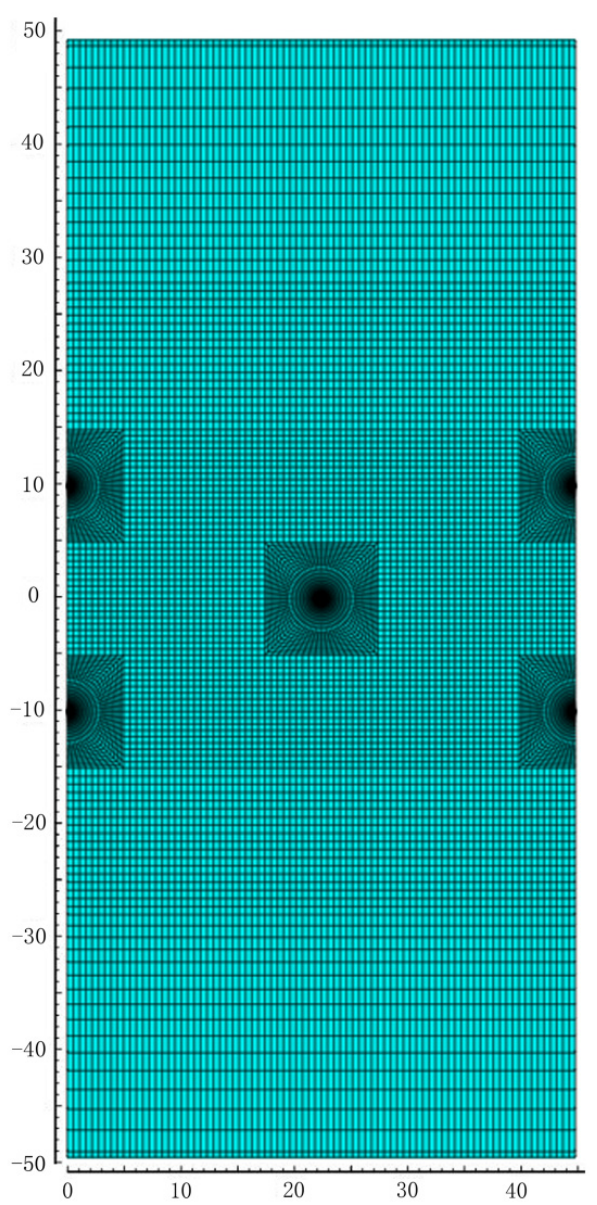

(b)

Figure 3. Configuration of (a) the five-spot well system in the hydrate deposit; and (b) the corresponding 2-D hybrid mesh.

\subsection{Initial and Boundary Conditions}

The initial conditions of the hydrate deposit are determined by the methods described by Li et al. [22]. The pressure and temperature of each gridblock are calculated, respectively, by the following two equations:

$$
\begin{gathered}
P=\rho_{r} g H+\rho_{w} g(h-H)+P_{0} \\
T=273.15+G_{2}(h-H)
\end{gathered}
$$

where $\rho_{r}$ is the rock density of the permafrost layer $\left(2000 \mathrm{~kg} / \mathrm{m}^{3}\right)[8], \rho_{w}$ is the aqueous density under the permafrost layer $\left(1000 \mathrm{~kg} / \mathrm{m}^{3}\right), g$ is the gravity $\left(9.81 \mathrm{~m} / \mathrm{s}^{2}\right), P_{0}$ is the atmospheric pressure $\left(1.01 \times 10^{5} \mathrm{~Pa}\right), h$ is the depth of a given gridblock, and $H$ is the thickness of the permafrost layer underground. It is calculated by

$$
H=\left(273.15-T_{0}\right) / G_{1}
$$


The basic parameters of $T_{0}, G_{1}$ and $G_{2}$ shown in Table 1 are determined based on field measurements [7,8]. Then the initial temperature and pressure at the bottom of the HBL $\left(T_{\mathrm{B}}\right.$ and $\left.P_{\mathrm{B}}\right)$ are initialized to be 277.84 $\mathrm{K}$ and 4.19 MPa, respectively (Table 1). In this study, $P_{\mathrm{B}}$ is a little higher than the equilibrium pressure so that such system is easy to be destabilized under mild depressurization driving force [22]. The pressures and temperatures of the top and bottom boundary layers are computed to be $3.43 \mathrm{MPa}$, 275.76 $\mathrm{K}$ and 4.41 $\mathrm{MPa}, 278.51 \mathrm{~K}$, respectively, and they are maintained fixed during the whole production period. In addition, the initial hydrate and aqueous saturations are set to be $S_{\mathrm{H}}=0.40$ and $S_{\mathrm{A}}=0.60$ in the HBL, respectively. The pores of the OB and UB are considered to be fully saturated with water $\left(S_{\mathrm{A}}=1.0\right)$, indicating no free gas in the system. All the conditions of the grid will not change until a disturbance is involved from outside.

\section{Simulation Results}

\subsection{Production Behaviors of the 5S System}

The novel five-spot horizontal well system is employed for the gas production from the hydrate reservoirs of DK-2 drilling well in the Qilian Mountain permafrost. The combination method of heat injection and depressurization is used to promote the hydrate dissociation. Heat is supplied from the central well (Well_0) to the hydrate deposit with a constant rate $Q_{\text {inj }}$ by circulating hot water in the well or by methane gas combustion or electrical heating. A total of three cases with $Q_{\text {inj }}=27.2,54.4$ and 108.8 W per meter well length are simulated. The selected heat injection rates could eliminate the possibility of production abortion caused by severe ice formation. Meanwhile, all the four production wells (Well_1-Well_4) are operated under depressurization regime, and the production pressure $P_{\mathrm{W}}$ is set to be $0.101 \mathrm{MPa}(1 \mathrm{~atm})$ in each case, which could provide the possible maximum depressurization driving force $\Delta P_{\mathrm{W}}=P_{\mathrm{w} 0}-P_{\mathrm{W}}$ for hydrate dissociation. Here $P_{\mathrm{w} 0}$ is the initial pressure of the production well, and it is initialized to be 3.82 and $4.02 \mathrm{MPa}$ for the upper and lower two wells, respectively. The case of $Q_{\mathrm{inj}}=54.4 \mathrm{~W}$ and $P_{\mathrm{W}}=0.101 \mathrm{MPa}$ in the $5 \mathrm{~S}$ system is chosen to be the reference case (Ref.).

\subsubsection{Gas Production Using the 5S System}

Figure 4 shows the evolution of (a) the methane production rate $Q_{\mathrm{P}}$; and (b) the cumulative volume of the produced gas $V_{\mathrm{P}}$ using both the $5 \mathrm{~S}$ and $2 \mathrm{~S}$ systems under different $Q_{\text {inj }}$ in the DK-2 hydrate deposit. It is shown in Figure $4 \mathrm{a}$ that $Q_{\mathrm{P}}$ firstly decreases slightly in the early production period (less than 1000 days), and then it increases obviously due to the gas diffusion from the dissociated areas around the injection well to the production wells. In the reference case $\left(Q_{\text {inj }}=54.4 \mathrm{~W}\right)$, the maximum of $Q_{\mathrm{P}}$ is about $8.72 \mathrm{~m}^{3} /$ day $/ \mathrm{m}$ of well for the simulated zone. After that, $Q_{\mathrm{P}}$ keeps on reducing to a relatively low level, which is caused by the decreased heat utilization efficiency in the later production stage. In addition, Figure $4 \mathrm{a}$ also shows that $Q_{\mathrm{P}}$ increases with the rise of heat injection rate $Q_{\text {inj }}$ in most of the production time, which indicates the acceleration effect of the injected heat on the hydrate dissociation process. 


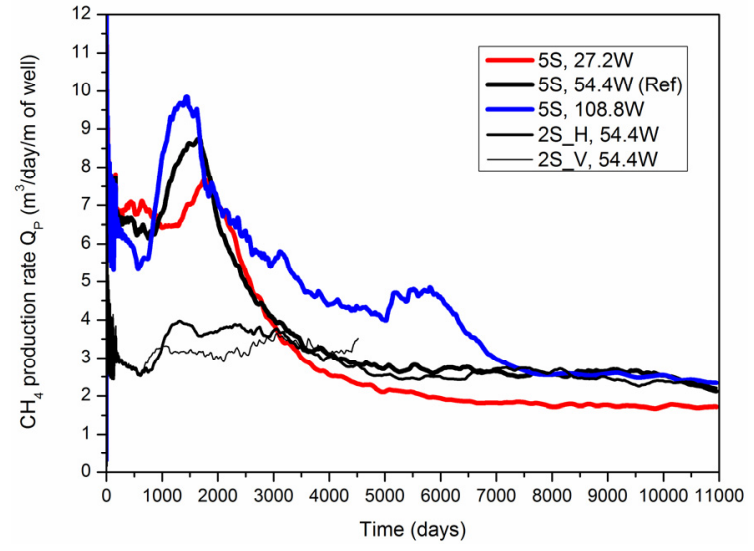

(a)

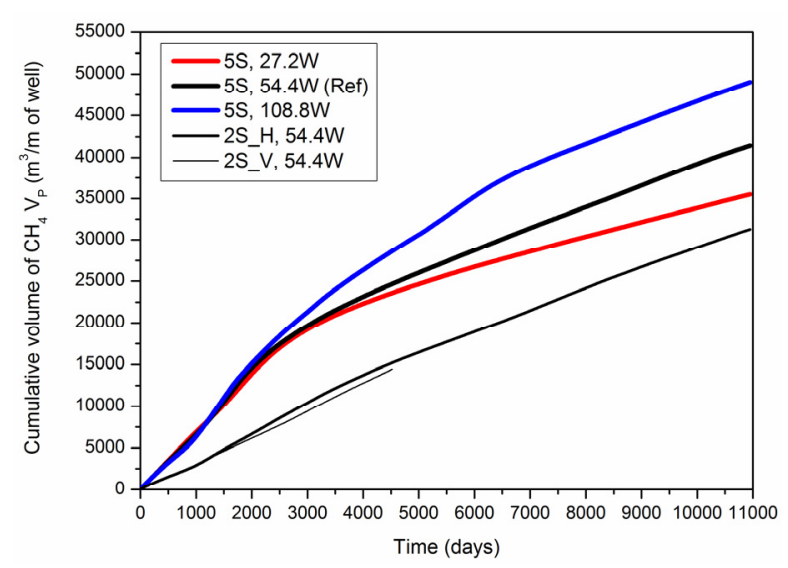

(b)

Figure 4. Evolution of (a) the $\mathrm{CH}_{4}$ production rate $Q_{\mathrm{P}}$; and (b) the cumulative volume of the produced $\mathrm{CH}_{4} V_{\mathrm{P}}$ from the five-spot and two-spot horizontal well systems under different heat injection rate in the DK-2 hydrate deposit.

Figure $4 \mathrm{~b}$ shows that $V_{\mathrm{P}}$ also increases continuously during the whole production period, while the rate of increase of $V_{\mathrm{P}}$ in the early stage is obviously higher than that in the following stage. This is in accordance with the change characteristics of the $Q_{\mathrm{P}}$ profiles shown in Figure $4 \mathrm{a}$. The total volume of the obtained methane in 30 years is approximately $4.14 \times 10^{4} \mathrm{ST} \mathrm{m}^{3}$ in the reference case. Assuming that the length of the well along the $y$ axis is $L_{\mathrm{y}}(\mathrm{m})$, and the number of the identical unit in the 5S system is $N(N \geq 3$, Figure $2 \mathrm{c}), V_{\mathrm{P}}$ will attain about $4.14 \times 10^{4} N L_{\mathrm{y}} \mathrm{ST} \mathrm{m}^{3}$ for the entire hydrate deposit at $t=30$ years in this case. The $N$ is calculated as:

$$
N=\frac{L_{x}}{2 \Delta l_{\text {I-P }}}
$$

where $L_{\mathrm{x}}$ is the width of the hydrate deposit along the $x$ axis. When the $Q_{\text {inj }}$ is raised from $27.2 \mathrm{~W}$ to $54.4 \mathrm{~W}$ and further to $108.8 \mathrm{~W}$, the gas production performance could be generally enhanced, as shown in Figure $4 \mathrm{~b}$. However, the differences among the three curves are not notable at the early stage (about five years). It indicates that the gas production is mainly promoted by the depressurization in this period, and the effect of the injected heat is delayed due to the distance between the injection and production wells.

\subsubsection{Water Production and Hydrate Dissociation Rates}

Figure 5 shows the evolution of (a) the water production rate $Q_{\mathrm{w}}$; and (b) the total mass of the produced water $M \mathrm{w}$ using both the $5 \mathrm{~S}$ and $2 \mathrm{~S}$ systems under different $Q_{\text {inj }}$ in the DK-2 hydrate deposit. In the reference case $\left(Q_{\mathrm{inj}}=54.4 \mathrm{~W}\right), Q_{\mathrm{w}}$ firstly declines to the lowest level of about $64 \mathrm{~kg} / \mathrm{day} / \mathrm{m}$ of well in the early 1900 days, during which the gas production rate is just located at a relatively high level, as shown in Figure 4a. This is because when the high-pressure gas around the injection well diffuses to the production wells, the gas saturation increases obviously. It results in a larger relative permeability for the gas flow, while most of the water dissociated from hydrate is mainly retained in the pores of the porous media. This phenomenon can be also observed in the following period, when the $Q$ w starts to rise continuously with the decrease of $Q_{\mathrm{P}}$. As the amplitude of variation of $Q_{\mathrm{w}}$ is not severe in Figure 5a, $M_{\mathrm{W}}$ nearly increases linearly with time in the whole production period, as shown in Figure $5 \mathrm{~b}$. The total 
mass of water attains about $9.16 \times 10^{5} \mathrm{~kg}$ (=916 tons) in the end for the simulated single unit, and the corresponding average production rate is $83.65 \mathrm{~kg} / \mathrm{day} / \mathrm{m}$ of well, which is in the range of the $Q_{\mathrm{w}}$ curve and is manageable using currently available technology. It is also shown in Figure 5 that both $Q$ w and $M \mathrm{w}$ change little under different heat injection rates. It means that the water production is not sensitive to the injected heat in the $5 \mathrm{~S}$ system.

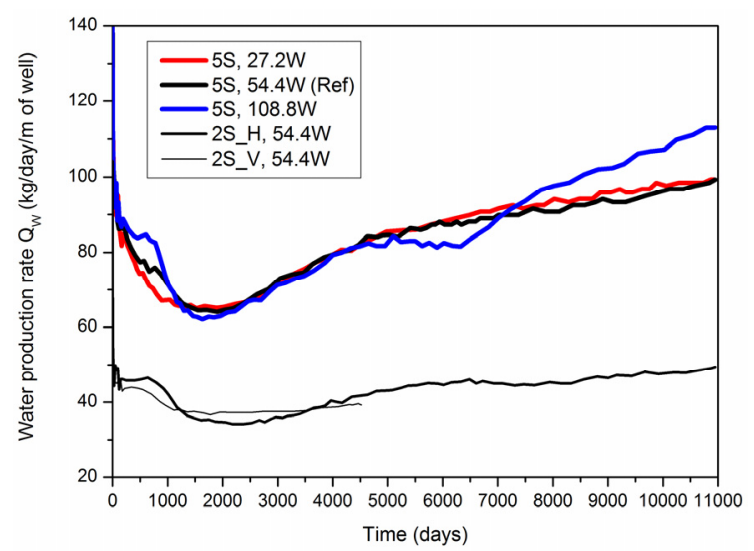

(a)

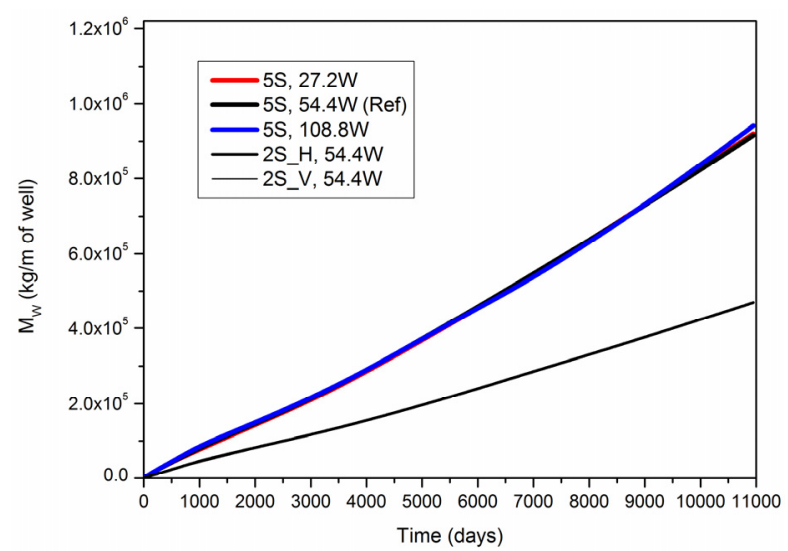

(b)

Figure 5. Evolution of (a) the water production rate $Q_{\mathrm{w}}$; and (b) the total mass of the produced water $M \mathrm{w}$ from the five-spot and two-spot horizontal well systems under different heat injection rate in the DK-2 hydrate deposit.

As another direct measure to evaluate the effectiveness of the proposed production method and the multi-well system, the hydrate dissociation percentage $\chi$ is defined as the ratio of the dissociated hydrate to its total amount. Figure 6 shows the profiles of the $\chi$ during gas production using the $5 \mathrm{~S}$ and $2 \mathrm{~S}$ systems under different $Q_{\text {inj }}$ in the DK-2 hydrate deposit. We can see that the form of each curve is similar with that of the corresponding $V_{\mathrm{P}}$ curve shown in Figure $4 \mathrm{~b}$, which indicates that the produced gas is mainly originated from the dissociated hydrate. For the reference case, $\chi$ approaches about $82.57 \%$ at the end of production process. In addition, it increases with the increase of $Q_{\text {inj }}$ due to the acceleration effect of heat injection on hydrate dissociation. Almost all the hydrate in the domain can be completely decomposed under the condition of $Q_{\text {inj }}=108.8 \mathrm{~W}$ in the $5 \mathrm{~S}$ system.

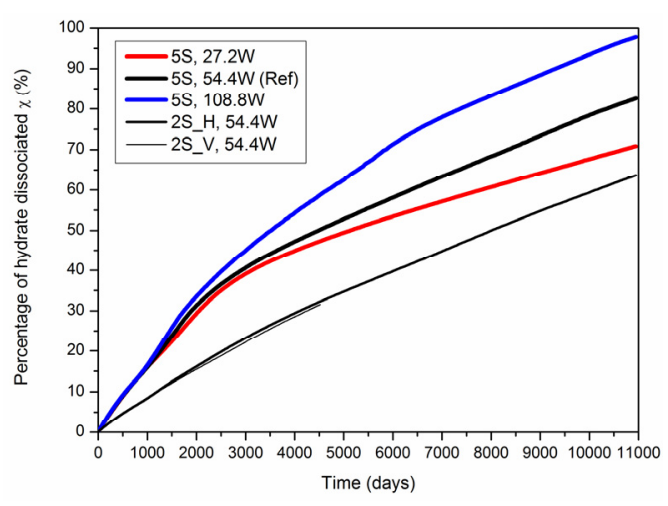

Figure 6. Evolution of the hydrate dissociation percentage $\chi$ during gas production from the five-spot and two-spot horizontal well systems under different heat injection rate in the DK-2 hydrate deposit. 


\subsubsection{Gas-to-Water Ratio And Energy Ratio}

Figure 7 shows the evolution of the gas-to-water ratio $R_{\mathrm{GW}}$ during gas production from the five-spot and two-spot horizontal well systems under different $Q_{\text {inj }}$ in the DK-2 hydrate deposit. The gas-to-water ratio is calculated to be $R_{\mathrm{GW}}=V_{\mathrm{P}} / V_{\mathrm{W}}$, where $V_{\mathrm{W}}=M_{\mathrm{w}} / 1000$ is the standard volume of the produced water $\left(\mathrm{m}^{3}\right)$. It is used as a relative criterion to assess the production performance of the employed $5 \mathrm{~S}$ system. In the reference case, $R_{\mathrm{GW}}$ rises persistently to the maximum value of 99.84 in about 2000 days. This is because the water production is inhibited by the gas production during this period, as discussed in Figures $4 \mathrm{a}$ and $5 \mathrm{a}$. After that, $R_{\mathrm{GW}}$ gradually declines with time due to the decreased gas production rate and the increased water production rate. On the other hand, Figure 7 also shows that higher $Q_{\text {inj }}$ will generally result in larger $R_{\mathrm{GW}}$ in the $5 \mathrm{~S}$ system, as the gas production (Figure 4 ) and the hydrate dissociation (Figure 6) are both more favorable with higher $Q_{\text {inj. }}$.

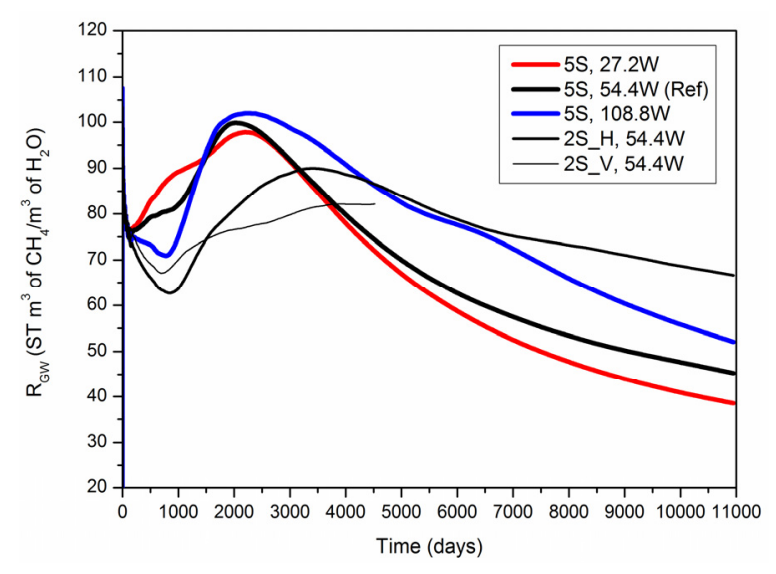

Figure 7. Evolution of the gas-to-water ratio $R_{\mathrm{GW}}$ during gas production from the five-spot and two-spot horizontal well systems under different heat injection rate in the DK-2 hydrate deposit.

Figure 8 presents the evolution of the energy ratio $\eta$ during gas production from the five-spot and two-spot horizontal well systems under different $Q_{\text {inj }}$ in the DK-2 hydrate deposit. The energy ratio is defined as the ratio of the obtained energy from methane gas to the energy consumed in the production time. The obtained energy can be generally represented by the total combustion enthalpy of the produced gas $\Delta H_{\mathrm{c}}\left(1 \mathrm{~atm}, 25^{\circ} \mathrm{C}, 889.6 \mathrm{~kJ} / \mathrm{mol}\right)$, while the consumed energy consists of the heat injection $Q$ and the pump work $W$. Then the energy ratio is expressed by the following equation:

$$
\eta=\Delta H_{\mathrm{c}} /(Q+W)
$$

The detailed calculation of these parameters can be found in the published literature [22]. It provides another relative criterion to evaluate the production efficiency of the $5 \mathrm{~S}$ system. 


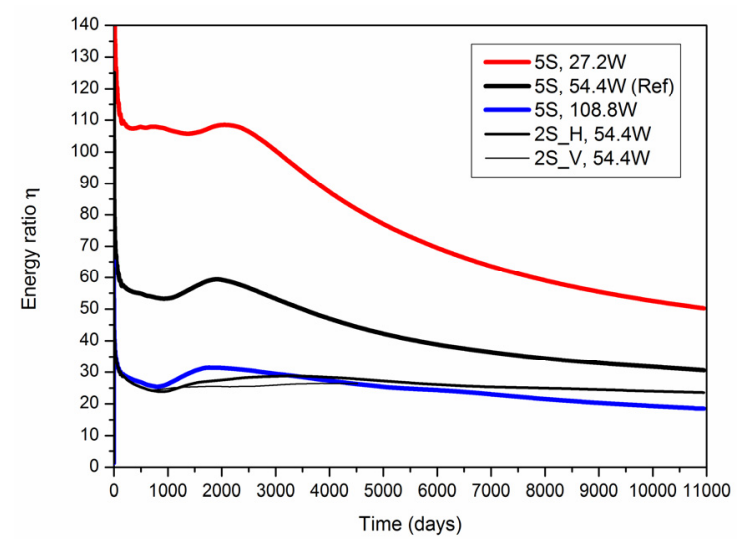

Figure 8. Evolution of the energy ratio $\eta$ during gas production from the five-spot and two-spot horizontal well systems under different heat injection rate in the DK-2 hydrate deposit.

Figure 8 shows that $\eta$ gradually rises to the maximum value of 59.32 during the period when the gas production rate increases with time in the reference case. Then it drops down continually because of the decreased hydrate dissociation and gas releasing rate. In addition, an obvious decline is observed when the $Q_{\text {inj }}$ is raised from 27.2 to $108.8 \mathrm{~W}$ in the three cases. It implies that higher heat injection rate will result in lower energy ratio due to the decreased thermal utilization efficiency. Considering the positive effect of $Q_{\text {inj }}$ on $V_{\mathrm{P}}$ and $R_{\mathrm{GW}}$ discussed above, the heat injection rate should be selected cautiously to obtain higher gas production rate and gas-to-water ratio while the energy ratio is still desirable.

\subsection{Comparison of the $5 S$ and $2 S$ Systems}

In this study, the two kinds of two-spot well system (2S_H and $\left.2 \mathrm{~S} \_\mathrm{V}\right)$ shown in Figure 2 are also employed for gas production from the hydrate deposit at site DK-2. There are 2 horizontal wells in each single unit, and they are placed horizontally in the 2S_H pattern and vertically in the $2 \mathrm{~S}$ _V pattern. We have carried out another two cases with the same operation conditions $\left(Q_{\mathrm{inj}}=54.4 \mathrm{~W}, P_{\mathrm{W}}=0.101 \mathrm{MPa}\right)$ to compare the production performance of the $2 \mathrm{~S}$ system with that of the $5 \mathrm{~S}$ system. The simulated results of the two cases in the same domain have also been shown in Figures $4-8$. The simulation process of the 2S_V case is aborted at about $t=4500$ days due to the tremendous secondary hydrate formation and the corresponding blocking effect on the fluids flow between the two wells.

It is shown in Figures 4 and 6 that the $Q_{\mathrm{P}}, V_{\mathrm{P}}$ and $\chi$ of the $2 \mathrm{~S} \_\mathrm{H}$ and $2 \mathrm{~S} \_\mathrm{V}$ cases are all obviously lower than those of the reference case, which means that a faster production process could be acquired using the $5 \mathrm{~S}$ design. As the water production curves of the two cases shown in Figure 5 are both situated at a relatively lower level, the $R_{\mathrm{GW}}$ gradually rises to a higher position than the reference case in Figure 7. On the other hand, Figure 8 shows that the energy ratio of the $2 \mathrm{~S}$ system is always smaller than that of the $5 \mathrm{~S}$ design under the same operation conditions. Regardless of the manageable water production under current technology, the $5 \mathrm{~S}$ system will be more commercially profitable for the hydrate exploitation from the Qilian Mountain permafrost.

Generally, desirable gas production rate, gas-to-water ratio, and energy ratio could be obtained when using the depressurization and thermal stimulation methods in the five-spot horizontal well system in the DK-2 hydrate deposit. In addition, the $5 \mathrm{~S}$ system is found to be more suitable than the $2 \mathrm{~S}$ configurations for gas production from permafrost hydrate deposits. 


\subsection{Spatial Distributions}

\subsubsection{Spatial Distributions of $S_{\mathrm{H}}$ and $S_{\mathrm{G}}$}

Figures 9 and 10 show the evolution of the spatial distributions of $S_{\mathrm{H}}$ and $S_{\mathrm{G}}$ during the 30 -year production period using the $5 \mathrm{~S}$ system in the reference case. The selected time points are $t=1,5,10,15$, 20 , and 30 years, respectively. The initial locations of the HBL boundaries are represented by two white lines. It is shown in Figure 9a that the hydrate in the vicinity of the wells is firstly dissociated, and the dissociation occurs in five cylindrical interfaces. The regenerated hydrate around the central injection well is notable, which is because of the gas diffusion from Well_0 to the low-temperature regions. The dissociation interfaces around the production wells gradually expand to the central one, and they are finally connected with each other at about $t=5$ years, as shown in Figure $9 \mathrm{~b}$. After that, the hydrate in the high- $S_{\mathrm{H}}$ regions around Well_0 begins to be dissociated under the synergistic effect of depressurization and heat injection (Figure 9c-f). Note that the hydrate dissociated areas are approximately symmetrically distributed in the domain along the line of $x=22.5 \mathrm{~m}$. In addition, the secondary hydrate formed near the upper and lower boundaries of the HBL reduces the effective permeability obviously [36], and it could further restrict the water flow from the OB and UB to the production wells.
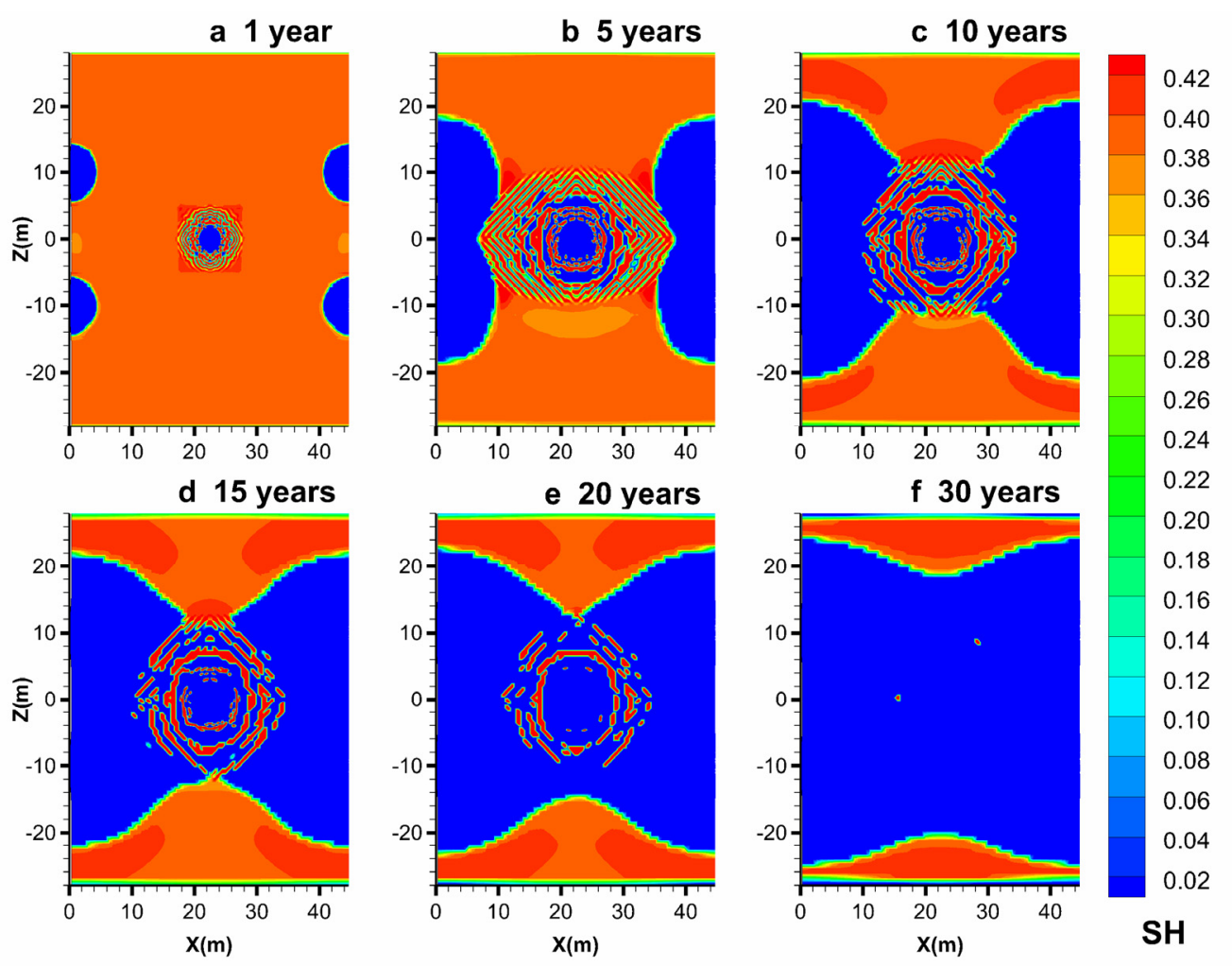

Figure 9. Evolution of the spatial distribution of $S_{\mathrm{H}}$ when $Q_{\mathrm{inj}}=54.4 \mathrm{~W}$ during gas production from the five-spot well system at site DK-2. 

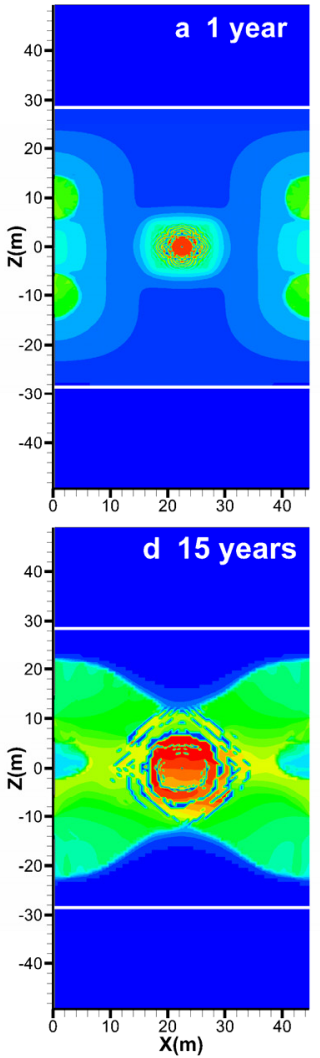
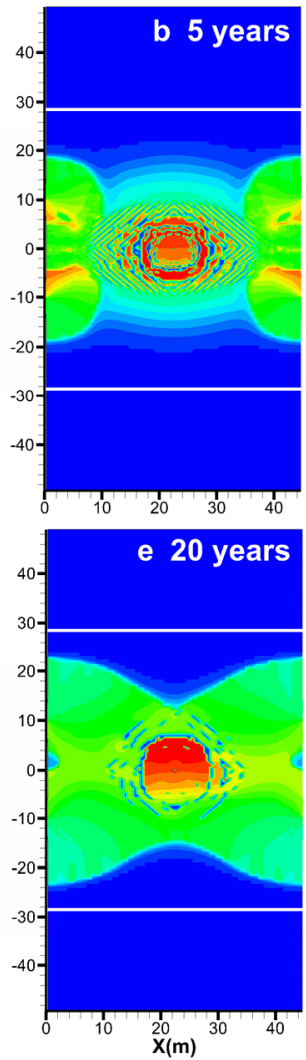

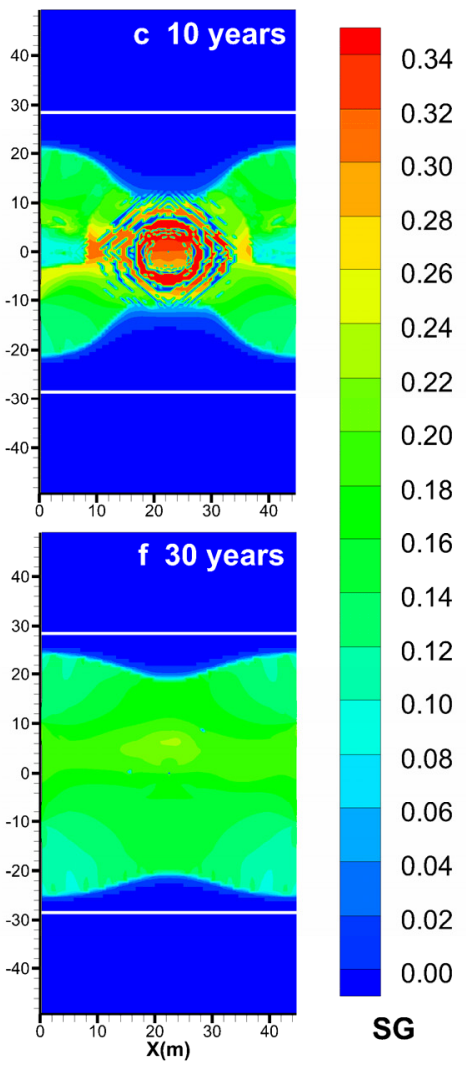

Figure 10. Evolution of the spatial distribution of $S_{\mathrm{G}}$ when $Q_{\text {inj }}=54.4 \mathrm{~W}$ during gas production from the five-spot well system at site DK-2.

Figure 10a shows that the released gas around Well_0 could not flow effectively to the production wells due to the impeding effect of the regenerated secondary hydrate in Figure 9a. Therefore, the produced gas in the early stage in Figure 4 is mainly originated from the depressurization-induced hydrate dissociation near the four production wells. As the dissociation interfaces gradually expand to each other (Figure 10b), some of the accumulated gas near the injection well could finally be produced from the production wells, which results in an increased gas production rate discussed in Figure 4. In the following period, the high- $S_{\mathrm{G}}$ region (defined as $S_{\mathrm{G}}>0.34$ ) around Well_0 does not disappear until the secondary hydrate is completely dissociated, as shown in Figure 10c-f. In addition, there is no gas escaping toward the $\mathrm{OB}$ and $\mathrm{UB}$ due to the impeding effect of the undissociated hydrate near the boundaries of the HBL.

\subsubsection{Spatial Distribution of $T$}

Figure 11 shows the evolution of the spatial distribution of $T$ during the 30-year production period using the $5 \mathrm{~S}$ system in the reference case. The following characteristics can be observed: (i) the temperatures near the production wells decrease sharply due to the sensible heat adsorption by the hydrate decomposition (Figure 11a); (ii) the injected heat does not take obvious effect on the gas production until the expansion of the low- $T$ region $\left(T<0.5^{\circ} \mathrm{C}\right)$ is large enough to meet the thermal effect area around Well_0, as shown in Figure 11b; (iii) the low-T regions gradually shrink with time when the injected heat could be more effectively transferred by conduction and convection with gas and water flow in the HBL (Figure 11c-f); (iv) the highest temperature of the reservoir is only about $19.3{ }^{\circ} \mathrm{C}$, which indicates low heat loss during the production process. 

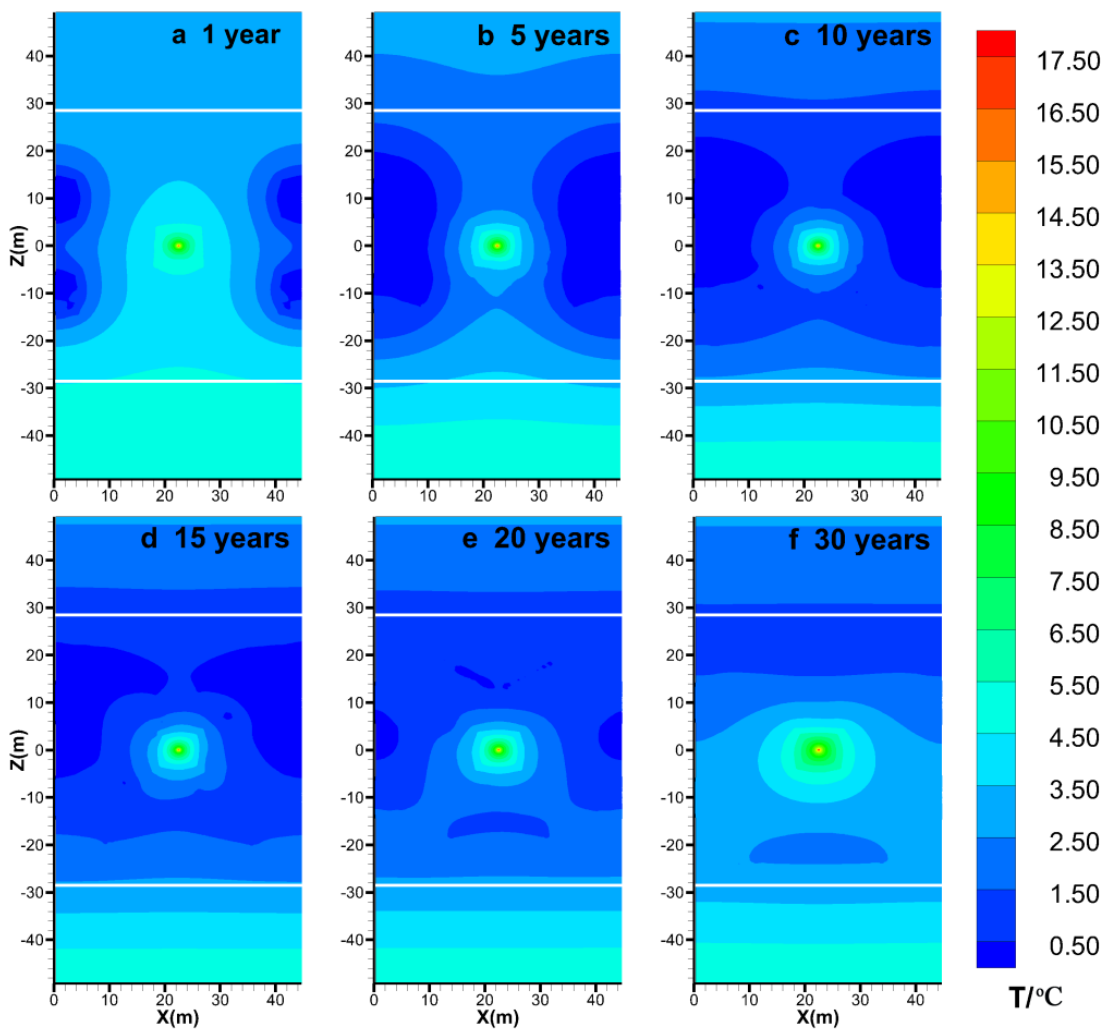

6.50

5.50

4.50

3.50

2.50

1.50

0.50

9.50

8.50

7.50

6.50

5.50

4.50

3.50

2.50

1.50

0.50

Figure 11. Evolution of the spatial distribution of $T$ when $Q_{\text {inj }}=54.4 \mathrm{~W}$ during gas production from the five-spot well system at site DK-2.

\subsubsection{Spatial Distribution of $S_{\mathrm{I}}$}

Figure 12 shows the evolution of the spatial distribution of $S_{\mathrm{I}}$ in the HBL during the 30 -year production period using the $5 \mathrm{~S}$ system in the reference case. In the early stage of the production (Figure 12a), large amount of sensible heat of the hydrate deposit is consumed by the hydrate dissociation under the sharp depressurization driving force. Then some of the water in the pores is transformed into solid ice near the production wells to provide additional latent heat for further hydrate dissociation [37]. The ice transition process gets more severe until the injected heat is successfully transferred to these areas, as shown in Figure 12b. After that, the formed ice is gradually melted by the injected heat (Figure 12c-f), and it could eliminate the possibility of complete flow blockage between the injection and production wells.

\subsubsection{Spatial Distribution of $P$}

Figure 13 shows the evolution of the spatial distribution of $P$ during the 30 -year production period using the 5S system in the reference case. It is shown in Figure 13a that the pressure around Well_0 rises continuously to a level higher than all the other areas in the early stage. This is caused by the gas accumulation when the flow conditions are still unfavorable for the gas diffusion. On the other hand, this high pressure gradient also provides necessary conditions for the secondary hydrate formation in Figure 9. Once the flow blockage between the injection and production wells becomes partially alleviated (Figure 13b), the high pressure area gradually disappears due to the gas release under the pressure gradient. Furthermore, the evolution of the $P$ distribution is not fierce in the following stage (Figure 13c-f), which indicates a relatively stable hydrate dissociation and gas production process. 

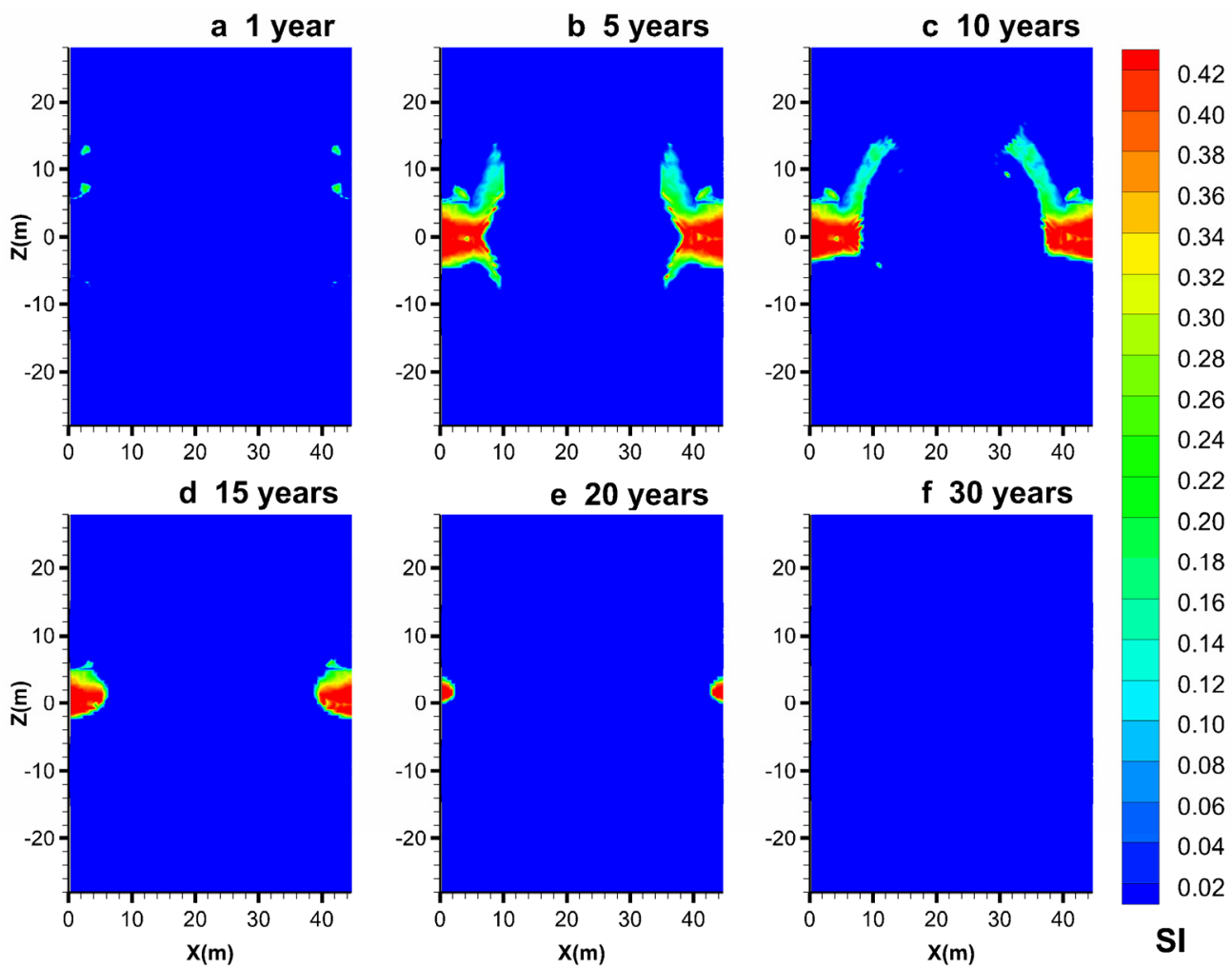

Figure 12. Evolution of the spatial distribution of $S_{\mathrm{I}}$ when $Q_{\text {inj }}=54.4 \mathrm{~W}$ during gas production from the five-spot well system at site DK-2.
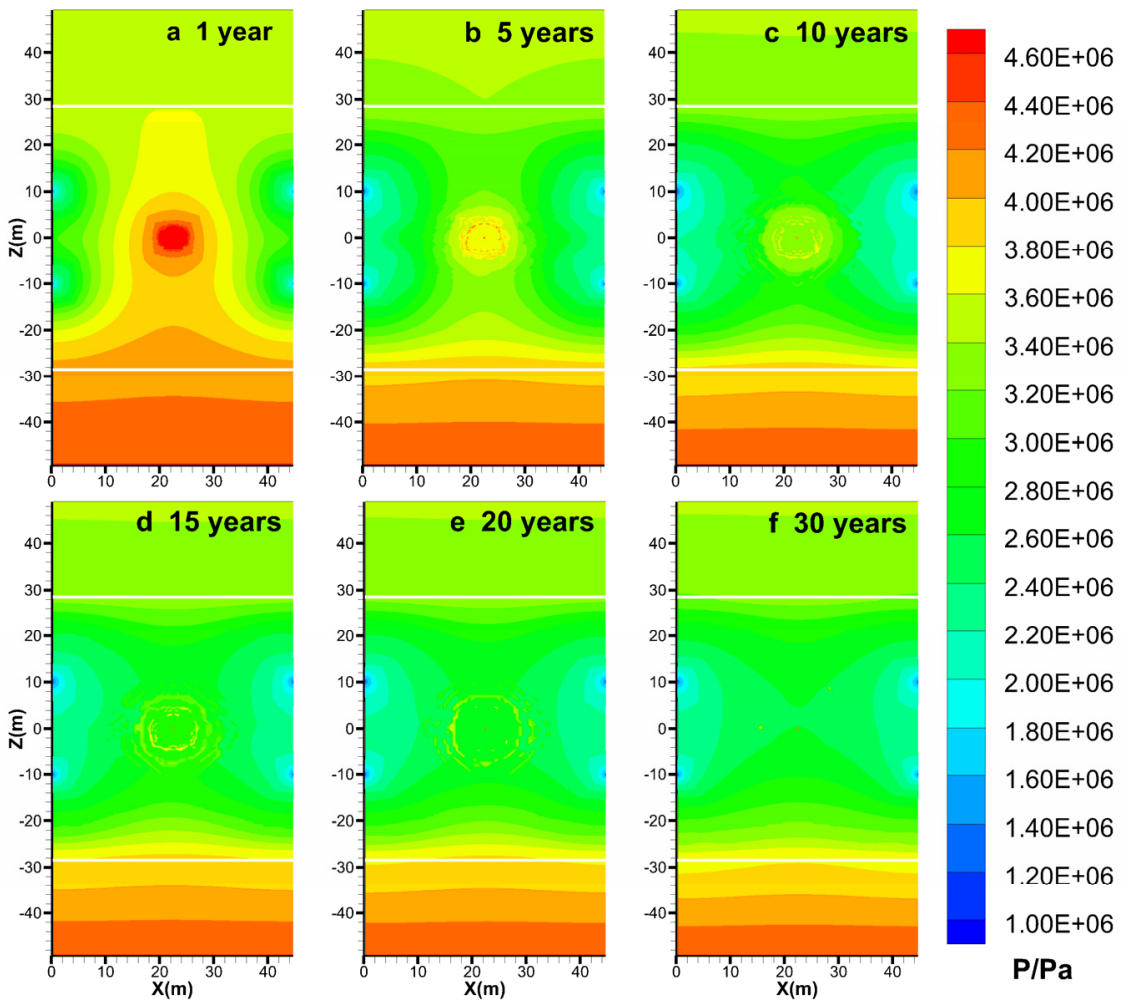

Figure 13. Evolution of the spatial distribution of $P$ when $Q_{\text {inj }}=54.4 \mathrm{~W}$ during gas production from the five-spot well system at site DK-2. 


\subsection{Dependence of Gas Production on the Well Spacing}

Previous studies $[15,25,26]$ have demonstrated that the gas production performance of the multi-well systems is dependent on the operation conditions and the geologic properties of the hydrate deposit, while the dependences of the gas production on the configurations of the multi-well itself (e.g., the well spacing) are still unknown. Therefore, we further carry out another two cases with different $\Delta l_{\text {I-P }}$ and $\Delta l_{\text {P-P }}$ to investigate the effect of the well spacing on the gas production in the $5 \mathrm{~S}$ system. In the reference case, $\Delta l_{\text {I-P }}$ and $\Delta l_{\mathrm{P}-\mathrm{P}}$ are set to be 22.5 and $20.0 \mathrm{~m}$, respectively. The width of the entire hydrate deposit $L_{\mathrm{x}}$ is assumed to be $315.0 \mathrm{~m}$ along the $x$ axis, while the length of the well $L_{\mathrm{y}}$ is still set to be $1.0 \mathrm{~m}$.

Figures 14 and 15 show the effect of the $\Delta l_{\mathrm{I}-\mathrm{P}}$ and $\Delta l_{\mathrm{P}-\mathrm{P}}$ on $V_{\mathrm{P}}, R_{\mathrm{GW}}, \chi$ and $\eta$ during gas production from the $5 \mathrm{~S}$ system. When the $\Delta l_{\text {I-P }}$ is reduced from 22.5 to $17.5 \mathrm{~m}$, the number of the identical unit $N$ in Equation (4) rises from 7 to 9, and the injected heat from Well_0 can be more easily transferred to the dissociation interface due to the decreased distance. Then both $V_{\mathrm{P}}$ and $\chi$ show an obvious increase when comparing with the reference case. Meanwhile, both the $R_{\mathrm{GW}}$ and $\eta$ rise to a higher level in the first several years, and then they drop down to approximately the same level with the reference case due to the larger amount of water production and heat consumption in the case of $\Delta l_{\mathrm{I}-\mathrm{P}}=17.5 \mathrm{~m}$. On the other hand, when the $\Delta l_{\text {P-P }}$ is decreased from 20.0 to $15.0 \mathrm{~m}$, all the four curves in Figures 14 and 15 show little difference with the reference case, which indicates weak dependence of the gas production on the $\Delta l_{\mathrm{P}-\mathrm{P}}$ in the $5 \mathrm{~S}$ system. Generally, it is more preferred to set the five-spot well system with shorter $\Delta l_{\text {-P }}$ to enhance the gas production and hydrate dissociation rates in the Qilian Mountain permafrost hydrate deposits.

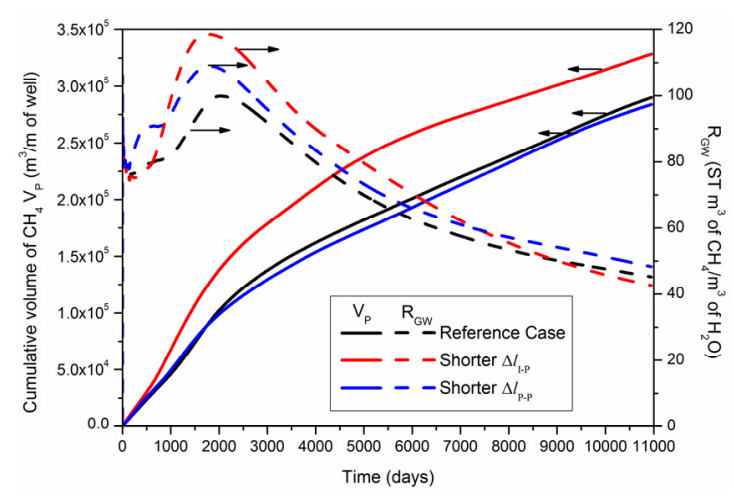

Figure 14. Effect of the $\Delta l_{\mathrm{I}-\mathrm{P}}$ and $\Delta l_{\mathrm{P}-\mathrm{P}}$ on $V_{\mathrm{P}}$ and $R_{\mathrm{GW}}$ during gas production from the five-spot well system.

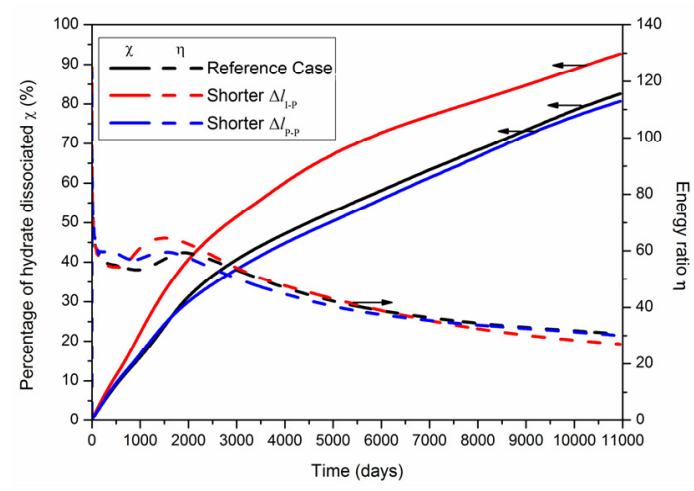

Figure 15. Effect of the $\Delta l_{\mathrm{I}-\mathrm{P}}$ and $\Delta l_{\mathrm{P}-\mathrm{P}}$ on $\chi$ and $\eta$ during gas production from the five-spot well system. 


\section{Conclusions}

In this numerical study, the five-spot horizontal well system is used for the exploitation of the DK-2 hydrate deposit in the Qilian Mountain. Based on the simulation results, the following conclusions can be drawn:

(1) Favorable gas production performance, including the gas production rate, the gas-to-water ratio and the energy ratio, could be obtained when using the $5 \mathrm{~S}$ system in the DK-2 hydrate deposit. It is found that the $5 \mathrm{~S}$ system will be more suitable than the $2 \mathrm{~S}$ configurations for the hydrate exploitation.

(2) The injected heat is a key factor that determines the overall production behaviors of the $5 \mathrm{~S}$ system. The heat injection rate should be selected cautiously to obtain higher gas production rate and gas-to-water ratio while the energy ratio is still desirable.

(3) The hydrate dissociation occurs in five cylindrical interfaces in the early stage, and the effect of the injected heat is not obvious until the flow channels become unobstructed. There is no gas escaping toward the $\mathrm{OB}$ and UB before the hydrate is completely dissociated near the boundaries of the HBL.

(4) Ice transition is observed to take place near the production wells of the $5 \mathrm{~S}$ system in the early production stage. The formed ice can be gradually melted by the injected heat to eliminate the possibility of complete flow blockage between the injection and production wells.

(5) The gas production characteristics of the $5 \mathrm{~S}$ system are dependent on the spacing of the horizontal wells. Generally, it is more preferred to set the five-spot well system with shorter $\Delta l_{\text {I-P }}$ to enhance the gas production rate, while the $\Delta l$ P-P shows less influence on the total gas produced in the same region.

\section{Acknowledgments}

The authors gratefully appreciate the Fundamental Research Funds for the Central Universities (Project Nos. 106112015CDJXY240002 and 106112015CDJZR245520) for providing financial aids in completing this work.

\section{Author Contributions}

The authors have contributed equally to the research and writing of this manuscript.

\section{Conflict of Interest}

The authors declare no conflict of interest.

\section{Nomenclature}

$G_{1}=$ thermal gradient within the frozen layer $\left({ }^{\circ} \mathrm{C} / \mathrm{m}\right)$

$G_{2}=$ thermal gradient below the frozen layer $\left({ }^{\circ} \mathrm{C} / \mathrm{m}\right)$

$H=$ permafrost thickness $(\mathrm{m})$

$k=$ intrinsic permeability $\left(\mathrm{m}^{2}\right)$ 
$k_{\text {eff }}=$ effective permeability $\left(\mathrm{m}^{2}\right)$

$k_{\mathrm{rA}}=$ aqueous relative permeability $\left(\mathrm{m}^{2}\right)$

$k_{\mathrm{rG}}=$ gas relative permeability $\left(\mathrm{m}^{2}\right)$

$k_{\Theta \mathrm{C}}=$ thermal conductivity $(\mathrm{W} /(\mathrm{m} \cdot \mathrm{K}))$

$k_{\Theta \mathrm{RD}}=$ thermal conductivity of dry porous medium $(\mathrm{W} /(\mathrm{m} \cdot \mathrm{K}))$

$k_{\Theta \mathrm{RW}}=$ thermal conductivity of fully saturated porous medium $(\mathrm{W}(\mathrm{m} \cdot \mathrm{K}))$

$k_{\Theta \mathrm{I}}=$ thermal conductivity of ice $(\mathrm{W} /(\mathrm{m} \cdot \mathrm{K}))$

$M \mathrm{w}=$ cumulative mass of produced water $(\mathrm{kg})$

$N=$ the number of identical unit

$P \quad=$ pressure $(\mathrm{Pa})$

$P_{\mathrm{B}}=$ initial pressure at base of $\operatorname{HBL}(\mathrm{Pa})$

$P_{\mathrm{W}}=$ pressure at the well $(\mathrm{Pa})$

$P_{\mathrm{W} 0}=$ initial pressure at the well $(\mathrm{Pa})$

$Q \quad=$ injected heat $(\mathrm{J})$

$Q_{\text {inj }}=$ heat injection rate $(\mathrm{W} / \mathrm{m}$ of well)

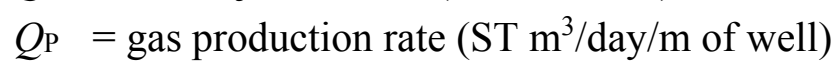

$Q_{\mathrm{W}}=$ average water production rate $(\mathrm{kg} / \mathrm{day} / \mathrm{m}$ of well)

$r \quad=$ radius $(\mathrm{m})$

$R_{\mathrm{GW}}=$ gas-to-water ratio $\left(\mathrm{ST} \mathrm{m}^{3}\right.$ of $\mathrm{CH}_{4} / \mathrm{m}^{3}$ of $\left.\mathrm{H}_{2} \mathrm{O}\right)$

$S \quad=$ phase saturation

$t \quad=$ time (days)

$T=$ temperature $\left({ }^{\circ} \mathrm{C}\right)$

$T_{0}=$ permafrost ground temperature $\left({ }^{\circ} \mathrm{C}\right)$

$T_{\mathrm{B}}=$ initial temperature at the base of $\mathrm{HBL}\left({ }^{\circ} \mathrm{C}\right)$

$V_{\mathrm{P}}=$ cumulative volume of produced $\mathrm{CH}_{4}\left(\mathrm{ST} \mathrm{m}^{3}\right)$

$W \quad=\operatorname{pump}$ work $(\mathrm{J})$

$x, y, z=$ cartesian coordinates $(\mathrm{m})$

$X_{\mathrm{S}}=$ salinity

$\Delta H_{\mathrm{c}}=$ combustion enthalpy of produced methane $(\mathrm{J})$

$\Delta l_{\text {I-P }}=$ horizontal distance between injector and producer $(\mathrm{m})$

$\Delta l_{\mathrm{P}-\mathrm{P}}=$ vertical distance between two producers $(\mathrm{m})$

$\Delta P_{\mathrm{W}}=$ driving force of depressurization, $P_{\mathrm{W} 0}-P_{\mathrm{W}}(\mathrm{Pa})$

$\Phi=$ porosity

$\eta \quad=$ energy ratio

$\chi \quad=$ hydrate dissociation percentage

$\lambda=$ van Genuchten exponent-Table 1

\section{Subcripts and Superscripts}

$0=$ denotes initial state

$\mathrm{A}=$ aqueous phase

$\mathrm{B}=$ base of $\mathrm{HBL}$

cap = capillary 
$\mathrm{G}=$ gas phase

$\mathrm{H}=$ solid hydrate phase

I = solid ice phase

irA $=$ irreducible aqueous phase

irG = irreducible gas

$n \quad=$ permeability reduction exponent - Table 1

$n_{\mathrm{G}}=$ gas permeability reduction exponent-Table 1

$\mathrm{OB}=$ overburden

$\mathrm{S}=$ salinity

$\mathrm{UB}=$ underburden

$\mathrm{W}=$ well

\section{References}

1. Sloan, E.D.; Koh, C.A. Clathrate Hydrates of Natural Gases, 3rd ed.; CRC Press: Boca Raton, FL, USA, 2008.

2. Moridis, G.J.; Collett, T.S.; Pooladi-Darvish, M.; Hancock, S.; Santamarina, C.; Boswell, R.; Kneafsey, T.; Rutqvist, J.; Kowalsky, M.B.; Reagan, M.T.; et al. Challenges, uncertainties, and issues facing gas production from gas-hydrate deposits. SPE Reserv. Eval. Eng. 2011, 14, 76-112.

3. Zhu, Y.H.; Zhang, Y.Q.; Wen, H.J.; Lu, Z.Q.; Wang, P.K. Gas hydrates in the Qilian Mountain permafrost and their basic characteristics. Acta Geosci. Sin. 2010, 31, 7-16. (In Chinese).

4. Lu, Z.Q.; Zhu, Y.H.; Zhang, Y.Q.; Wen, H.; Li, Y.H; Liu, C.L. Gas hydrate occurrences in the Qilian Mountain permafrost, Qinghai province, China. Cold Reg. Sci. Technol. 2011, 66, 93-104.

5. Wang, P.K.; Zhu, Y.H.; Lu, Z.Q.; Huang, X.; Pang, S.J; Zhang, S. Gas hydrate stability zone migration occurred in the Qilian Mountain permafrost, Qinghai, northwest China: Evidences from pyrite morphology and pyrite sulfur isotope. Cold Reg. Sci. Technol. 2014, 98, 8-17.

6. Zhu, Y.H.; Zhang, Y.Q.; Wen, H.J.; Lu, Z.Q.; Jia, Z.Y.; Li, Y.H.; Li, Q.H.; Liu, C.L.; Wang, P.K.; Guo, X.W. Gas hydrates in the Qilian Mountain permafrost, Qinghai, northwest China. Acta Geol. Sin. 2010, $84,1-10$.

7. Wu, Q.B.; Jiang, G.; Zhang, P. Assessing the permafrost temperature and thickness conditions favorable for the occurrence of gas hydrate in the Qinghai-Tibet Plateau. Energy Convers. Manag. 2010, 51, 783-787.

8. Lu, Z.Q.; Sultan, N.; Jin, C.S.; Rao, Z.; Luo, X.R.; Wu, B.H.; Zhu, Y.H. Modeling on gas hydrate formation conditions in the Qinghai-Tibet plateau permafrost. Chin. J. Geophys. 2009, 52, 157-168. (In Chinese)

9. Jiang, X.X.; Li, S.X.; Zhang, L.N. Sensitivity analysis of gas production from Class I hydrate reservoir by depressurization. Energy 2012, 39, 281-285.

10. Li, B.; Li, X.S.; Li, G.; Feng, J.C.; Wang, Y. Depressurization induced gas production from hydrate deposits with low gas saturation in a pilot-scale hydrate simulator. Appl. Energy 2014, 129, 274-286.

11. Giraldo, C.; Klump, J.; Clarke, M.; Schicks, J.M. Sensitivity analysis of parameters governing the recovery of methane from natural gas hydrate reservoirs. Energies 2014, 7, 2148-2176. 
12. Moridis, G.J.; Silpngarmlert, S.; Reagan, M.T.; Collett, T.; Zhang, K.N. Gas production from a cold, stratigraphically-bounded gas hydrate deposit at the Mount Elbert Gas Hydrate Stratigraphic Test Well, Alaska North Slope: Implications of uncertainties. Mar. Pet. Geol. 2011, 28, 517-534.

13. Schicks, J.; Spangenberg, E.; Giese, R.; Luzi-Helbing, M.; Priegnitz, M.; Beeskow-Strauch, B. A counter-current heat-exchange reactor for the thermal stimulation of hydrate-bearing sediments. Energies 2013, 6, 3002-3016.

14. Li, B.; Li, G.; Li, X.S.; Li, Q.P.; Yang, B.; Zhang, Y.; Chen, Z.Y. Gas production from methane hydrate in a pilot-scale hydrate simulator using the huff and puff method by experimental and numerical studies. Energy Fuels 2012, 26, 7183-7194.

15. Wang, Y.; Li, X.S.; Li, G.; Huang, N.S.; Feng, J.C. Experimental study on the hydrate dissociation in porous media by five-spot thermal huff and puff method. Fuel 2014, 117, 688-696.

16. Lee, J. Experimental study on the dissociation behavior and productivity of gas hydrate by brine injection scheme in porous rock. Energy Fuels 2010, 24, 456-463.

17. Li, G.; Li, X.S.; Tang, L.G.; Zhang, Y. Experimental investigation of production behavior of methane hydrate under ethylene glycol stimulation in unconsolidated sediment. Energy Fuels 2007, 21, 3388-3393.

18. Yuan, Q.; Sun, C.Y.; Yang, X.; Ma, P.C.; Ma, Z.W.; Liu, B.; Ma, Q.L.; Yang, L.Y.; Chen, G.J. Recovery of methane from hydrate reservoir with gaseous carbon dioxide using a three-dimensional middle-size reactor. Energy 2012, 40, 47-58.

19. Ors, O.; Sinayuc, C. An experimental study on the $\mathrm{CO}_{2}-\mathrm{CH}_{4}$ swap process between gaseous $\mathrm{CO}_{2}$ and $\mathrm{CH}_{4}$ hydrate in porous media. J. Pet. Sci. Eng. 2014, 119, 156-162.

20. Li, X.S.; Yang, B.; Li, G.; Li, B. Numerical simulation of gas production from natural gas hydrate using a single horizontal well by depressurization in Qilian Mountain permafrost. Ind. Eng. Chem. Res. 2012, 51, 4424-4432.

21. Zhao, J.F.; Yu, T.; Song, Y.C.; Liu, D.; Liu, W.G.; Liu, Y.; Yang, M.J.; Ruan, X.K.; Li, Y.H. Numerical simulation of gas production from hydrate deposits using a single vertical well by depressurization in the Qilian Mountain permafrost, Qinghai-Tibet plateau, China. Energy 2013, 52, 308-319.

22. Li, X.S.; Li, B.; Li, G.; Yang, B. Numerical simulation of gas production potential from permafrost hydrate deposits by huff and puff method in a single horizontal well in Qilian Mountain, Qinghai province. Energy 2012, 40, 59-75.

23. Moridis, G.J.; Reagan, M.T.; Boyle, K.L.; Zhang, K.N. Evaluation of the gas production potential of some particularly challenging types of oceanic hydrate deposits. Transp. Porous Media 2011, 90, 269-299.

24. Feng, J.C.; Li, X.S.; Li, G.; Li, B.; Chen, Z.Y.; Wang, Y. Numerical investigation of hydrate dissociation performance in the South China Sea with different horizontal well configurations. Energies 2014, 7, 4813-4834.

25. Li, B.; Li, G.; Li, X.S.; Chen, Z.Y.; Zhang, Y. The use of heat-assisted antigravity drainage method in the two horizontal wells in gas production from the Qilian Mountain permafrost hydrate deposits. J. Pet. Sci. Eng. 2014, 120, 141-153.

26. Li, B.; Li, X.S.; Li, G.; Chen, Z.Y. Evaluation of gas production from Qilian Mountain permafrost hydrate deposits in two-spot horizontal well system. Cold Reg. Sci. Technol. 2015, 109, 87-98. 
27. Sedaghat, M.H.; Ghazanfari, M.H.; Masihi, M.; Rashtchian, D. Experimental and numerical investigation of polymer flooding in fractured heavy oil five-spot systems. J. Pet. Sci. Eng. 2013, $108,370-382$.

28. Song, Z.J.; Li, Z.P.; Wei, M.Z.; Lai, F.P.; Bai, B.J. Sensitivity analysis of water-alternating-CO ${ }_{2}$ flooding for enhanced oil recovery in high water cut oil reservoirs. Comput. Fluids 2014, 99, 93-103.

29. Alajmi, A.F.; Gharbi, R.; Algharaib, M. The effect of heterogeneity and well configuration on the performance of hot water flood. J. Pet. Sci. Eng. 2014, 122, 524-533.

30. Wang, Y.; Li, X.S.; Li, G.; Zhang, Y.; Li, B.; Feng, J.C. A three-dimensional study on methane hydrate decomposition with different methods using five-spot well. Appl. Energy 2013, 112, 83-92.

31. Moridis, G.J.; Kowalsky, M.B.; Pruess, K. TOUGH + HYDRATE v1.1 User's Manual: A Code for the Simulation of System Behavior in Hydrate-Bearing Geologic Media; Lawrence Berkeley National Laboratory: Berkeley, CA, USA, 2009.

32. Li, G.; Li, B.; Li, X.S.; Zhang, Y.; Wang, Y. Experimental and numerical studies on gas production from methane hydrate in porous media by depressurization in pilot-scale hydrate simulator. Energy Fuels 2012, 26, 6300-6310.

33. Li, B.; Li, X.S.; Li, G. Kinetic studies of methane hydrate formation in porous media based on experiments in a pilot-scale hydrate simulator and a new model. Chem. Eng. Sci. 2014, 105, 220-230.

34. Li, G.; Li, X.S.; Li, B.; Wang, Y. Methane hydrate dissociation using inverted five-spot water flooding method in cubic hydrate simulator. Energy 2013, 64, 298-306.

35. Van Genuchten, M.T. A Closed-Form equation for predicting the hydraulic conductivity of unsaturated soils. Soil Sci. Soc. Am. J. 1980, 44, 892-898.

36. Li, B.; Li, X.S.; Li, G.; Jia, J.L.; Feng, J.C. Measurements of water permeability in unconsolidated porous media with methane hydrate formation. Energies 2013, 6, 3622-3636.

37. Li, B.; Liang, Y.P.; Li, X.S.; Wu, H.J. Numerical analysis of methane hydrate decomposition experiments by depressurization around freezing point in porous media. Fuel 2015, 159, 925-934.

(C) 2015 by the authors; licensee MDPI, Basel, Switzerland. This article is an open access article distributed under the terms and conditions of the Creative Commons Attribution license (http://creativecommons.org/licenses/by/4.0/). 